\title{
Dietary determinants of saturated fat intake in Irish pre-school children aged 1-4 years
}

\author{
L. Kehoe $^{1}$, J. Walton ${ }^{1}$, B.A. McNulty ${ }^{2}$, A.P. Nugent ${ }^{2}$ and A. Flynn ${ }^{1}$ \\ ${ }^{1}$ School of Food and Nutritional Sciences, University College Cork, Republic of Ireland and \\ ${ }^{2}$ UCD Institute of Food and Health, University College Dublin, Belfield, Dublin 4, Republic of Ireland
}

Elevated intakes of saturated fat are known to increase circulating LDL cholesterol concentrations and risk of cardiovascular disease (in both children and adults) ${ }^{(1,2)}$. However, emerging studies suggest the impact of saturated fat on health may be dependent on the food form (particularly relating to dairy foods) $)^{(3,4)}$. We have previously reported the mean intakes of saturated fat in Irish children $(15 \cdot 7,14 \cdot 8,14 \cdot 5 \text { and } 14 \cdot 1 \% \text { E at age } 1,2,3 \text { and } 4 \text {, respectively })^{(5)}$. We also identified that the patterns of intakes of saturated fat at age 4 years in Irish children will make it difficult to comply with recommendations for saturated fat intake in later childhood $(<10 \%$ of energy from age 5 years $)^{(6)}$. The objective of this analysis was to determine dietary sources of saturated fat in 1 to 4 year old Irish children and to investigate the dietary determinants of saturated fat intake at age 4 years. Analyses were based on the National Pre-School Nutrition Survey (2010-2011) (www.iuna.net) which used a 4-day weighed food record to collect food intake data of 500 pre-school children. Saturated fat intakes were determined based on published food composition tables and published papers as outlined elsewhere ${ }^{(7)}$. Dietary sources and determinants of saturated fat were calculated using SPSS ${ }^{\odot}$ software. On the basis of mean daily intake of saturated fat at age 4 years, participants were divided into three intake groups: low medium or high consumers. The food groups which accounted for the greatest proportion of the difference in intakes between the high (top third) and low (bottom third) consumers of saturated fat were identified.

Table 1. Contribution (\%) of food groups to saturated fat intake in Irish children

\begin{tabular}{|c|c|c|c|c|}
\hline \multirow[b]{2}{*}{ Food Group } & 1 year olds & 2 year olds & 3 year olds & 4 year olds \\
\hline & \multicolumn{4}{|c|}{$\%$} \\
\hline Milks & $42 \cdot 7$ & $28 \cdot 8$ & $24 \cdot 4$ & $21 \cdot 5$ \\
\hline Biscuits, cakes \& confectionery & $8 \cdot 7$ & $13 \cdot 3$ & $15 \cdot 9$ & $17 \cdot 9$ \\
\hline Meats & $11 \cdot 8$ & $13 \cdot 9$ & $14 \cdot 2$ & $14 \cdot 8$ \\
\hline Fat spreads \&oils & $5 \cdot 5$ & $8 \cdot 9$ & $10 \cdot 0$ & $8 \cdot 3$ \\
\hline Cheeses & $7 \cdot 4$ & $8 \cdot 2$ & $7 \cdot 3$ & $7 \cdot 9$ \\
\hline Creams & $2 \cdot 0$ & $3 \cdot 4$ & $4 \cdot 3$ & $5 \cdot 5$ \\
\hline Yoghurts & $6 \cdot 9$ & $5 \cdot 5$ & $5 \cdot 5$ & $5 \cdot 0$ \\
\hline Other foods & $15 \cdot 9$ & $20 \cdot 1$ & $20 \cdot 2$ & 21.4 \\
\hline
\end{tabular}

Table 2. Dietary determinants of saturated fat intake in 4 year old children

\begin{tabular}{|c|c|c|c|}
\hline \multicolumn{3}{|c|}{ Mean daily saturated fat intake $(\mathrm{g} / \mathrm{d})$} & \multirow{2}{*}{$\begin{array}{l}\% \text { Contribution of food groups to the difference between high } \\
\text { and low consumers }\end{array}$} \\
\hline Low & High & Difference & \\
\hline $13.8(11.6 \% \mathrm{E})$ & $26 \cdot 8(16 \cdot 8 \% \mathrm{E})$ & $13 \cdot 0(5 \cdot 2 \% \mathrm{E})$ & $\begin{array}{l}\text { Milks (27), Biscuits, cakes \& confectionery (14), Fat spreads \& oils (13), Meats (13), } \\
\text { Cheeses (12), Creams (5), Yoghurts (4), Breads \& rolls (3) Other foods (9) }\end{array}$ \\
\hline
\end{tabular}

Mean intakes of saturated fat in all consumer groups $(11.6,14.0$ and $16.8 \% \mathrm{E})$ were above the $<10 \% \mathrm{E}$ recommendation. The difference in saturated fat intake between high and low consumers was $13 \mathrm{~g} / \mathrm{d}$. Dairy products (including milks, cheeses, creams and yoghurts) contributed $48 \%$ of the difference in intakes between high and low consumers. 'Biscuits, cakes \& confectionery', 'fat spreads $\&$ oils', and meats contribute a further 14,13 and $13 \%$ of the difference. These findings, together with emerging evidence on saturated fat sources and health will aid in the development of dietary strategies to improve intakes of saturated fat for young children in Ireland.

The project was funded by the Irish Department of Agriculture, Food and the Marine under the Nutridata Project 13 F 542; 2014-2016.

1. Sanders TA (2013) Proc Nutr Soc 72, 390-398.

2. Juonala M, Viikari JS and Raitakari OT (2013) Curr Opin Lipidol 24, 57-64.

3. Huth PJ and Park KM (2012) Adv Nutr 3, 266-285.

4. Ericson U, Hellstrand S, Schulz Ca et al. (2015) Am J Clin Nutr 10, 1065-1080.

5. Walton J, Kehoe L, McNulty B et al. (2017) J Hum Nutr Diet DOI: 10.1111/jhn.12452

6. Department of Health UK (1991) United Kingdom: HMSO.

7. Li K, McNulty B, Tiernery AM et al. (2016) Br J Nutr 115, 1798-809. 